Journal of Advanced Research in Fluid Mechanics and Thermal Sciences

Journal homepage: www.akademiabaru.com/arfmts.html ISSN: 2289-7879

\title{
Study On The Application Of Thermoelectric Coolers Inside Unmanned Surface Vehicles
}

\author{
Muhammad Arif Budiyanto ${ }^{1,}{ }^{*}$, Nadhilah $^{1}$, Alif Hikmah Fikri ${ }^{1}$, Hanmah Ayuningtyas $^{1}$ \\ 1 Naval Architecture and Marine Engineering, Department of Mechanical Engineering, Universitas Indonesia, Kampus Baru UI Depok, Jawa Barat, \\ 16424, Indonesia
}

\section{ARTICLE INFO ABSTRACT}

Article history:

Received 1 October 2020

Received in revised form 21 February 2021

Accepted 23 February 2021

Available online 7 April 2021

\section{Keywords:}

Unmanned surface vehicle;

Thermoelectric cooler; Cooling system

\begin{abstract}
The development of unmanned surface vehicles for military and commercial needs is increasing as the development of autonomous control systems. The farther the operation range of unmanned surface vehicles makes the propulsion motor generated heat and decreased the performance of the vehicle. This study aims to analyze the application of a thermoelectric cooler to decrease the temperature of the electric motors as a propulsion system on the unmanned surface vehicle. The research was carried out by prototyping the thermoelectric cooler $12 \mathrm{~V}$ and tested at the prototype of unmanned surface vehicles with a length overall $1.5 \mathrm{~m}$. The results showed the application of a thermoelectric cooler potentially effective to decrease the electric motor temperature by as much as $26.3{ }^{\circ} \mathrm{C}$ by neglect the heat loss due to convection. The results of this study contributed to the development of reliable unmanned surface vehicles.
\end{abstract}

\section{Introduction}

The world demand for unmanned surface vehicles (USV) is expected to see the fastest development in the defense and industrial sector. USV can be described as an unmanned vehicle, performing tasks without human interference in a variety of messy environments, and showing a very nonlinear dynamic [1]. It is expected that further development of USV would deliver extraordinary benefits such as lower production and operating costs, wider operational range (reliability) and accuracy, greater autonomy, and enhanced versatility in a sophisticated environment $[2,3]$. USV may be built-in cost-effective ways for a range of possible applications, such as scientific research, environmental missions, military use and transportation uses [4-7]. The future success of USVs depends on the advancement of complete autonomy, efficient communication systems, and adequate performance in hull design [8]. Among the several USV studies, most researchers focus solely on the autonomous vehicle, work on the hull's performance seems to be lacking.

\footnotetext{
* Corresponding author.

E-mail address: arif@eng.ui.ac.id

https://doi.org/10.37934/arfmts.82.1.1220
} 
The performance of a ship's hull is influenced by many factors such as the shape of the hull itself, an efficient propulsion system as well as additional technologies such as hydrofoil or air bubble lubricant [9-13]. In terms of the propulsion system on USV, overall the development of this vehicle agreed to use motor propulsion that uses battery power. The electric marine propulsion system provides many advantages, namely not providing a mechanical drive system, giving operators direct control with an appropriate increase in maneuver response and freedom of installation arrangement that is not possible in a mechanical system that requires an in-line layout between the prime mover and the propeller $[14,15]$. However, the use of an electric propulsion system with a driving motor will generate heat during operation [16]. The increase in temperature due to the rotation of the brushless direct current motor can reach $60^{\circ} \mathrm{C}$ [17]. To prevent overheating, a cooling system can be made in the propulsion motor, there are two types of cooling systems namely the air or liquid systems [18].

As heat demand increases in electronic uses, the cooling technique has a significant effect on increasing its performance. Thermoelectric cooling techniques are one of a variety of cooling techniques that have been developed continuously to accomplish different applications. Research which considers the effects for electronic devices of heating heat loads and input currents on thermoelectric air conditioning modules [19]. Other research studies new thermoelectric self-cooling concepts which can be introduced as cooling and temperature control devices using thermoelectric technology without the consumption of electricity [20]. The application of nanofluids as a working fluid in a hot pipe liquid block combined with thermoelectric cooling [21]. Investigation of a thermoelectric generator model combined with a drain and a cooler for exhaust gas-based cooling systems [22]. Many experimental and numerical studies have investigated fluid flow and heat transfer in cooling mini-rectangular fins for cooling the Central processing unit [23-25]. Of the most research studies on thermoelectric cooling that focus on applications in electronic devices, very few researchers have tried to use thermoelectric cooling for propulsion systems in USV prototype boat models $[26,27]$. The use of a thermoelectric cooler in the propulsion system will provide benefits in increasing motor efficiency. From this research application gap, this paper aims to conduct an experimental study of the application of thermoelectric coolers to propulsion systems in unmanned surface vehicles. The contribution of the results of this study will be twofold, namely knowing the effectiveness of the application of thermoelectric coolers to decreasing the temperature of electric motors and providing an overview of the application of thermoelectric coolers on unmanned surface vehicles. This paper is part of the development of the autonomous surface vehicle technology developed by the Autonomous Marine Vehicle University of Indonesia [28].

\section{Methodology}

\subsection{Design of Unmanned Surface Vehicle}

Unmanned surface vehicles used in this study use monohull type and are designed for search and rescue vehicles. The designed USV has the main dimension, which is an overall length of 1.5 meters, a width of 0.4 meters, a height of 0.3 meters, and a draft of 0.06 meters. The prototype of USV in this study is shown in Figure 1. The propulsion system used on USV is using a water jet system with an electric motor drive that uses battery power. General description of the electronic system design on this USV is the controller using NodeMcu and ArduinoProMicro, loT protocol using Streaming Cloud through Firestore, Power of 12v-10ah, Brushless DC Motor 3674-KV2075, battery capacity of 6200 $\mathrm{mAh}$. The general plan of the propulsion system, the electronic system, and the cooling system on this USV are shown in Figure 2. 


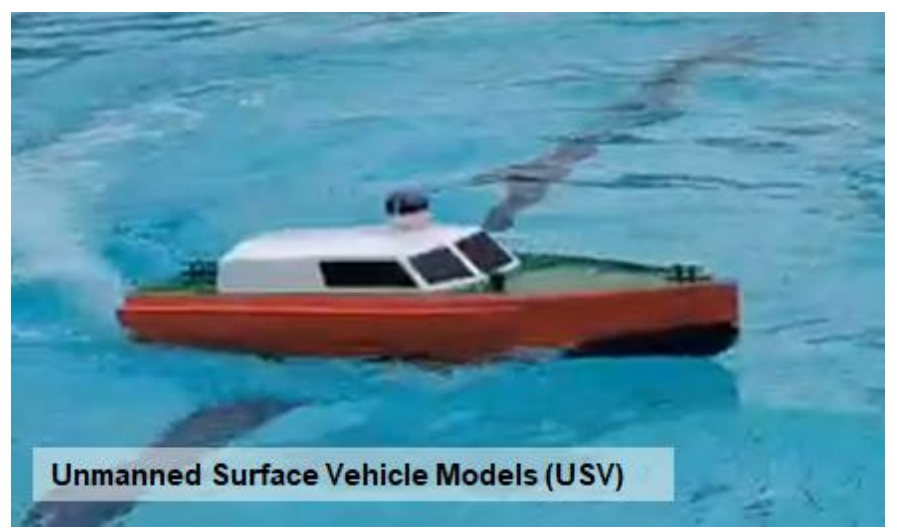

Fig. 1. The prototype of the Unmanned Surface Vehicle

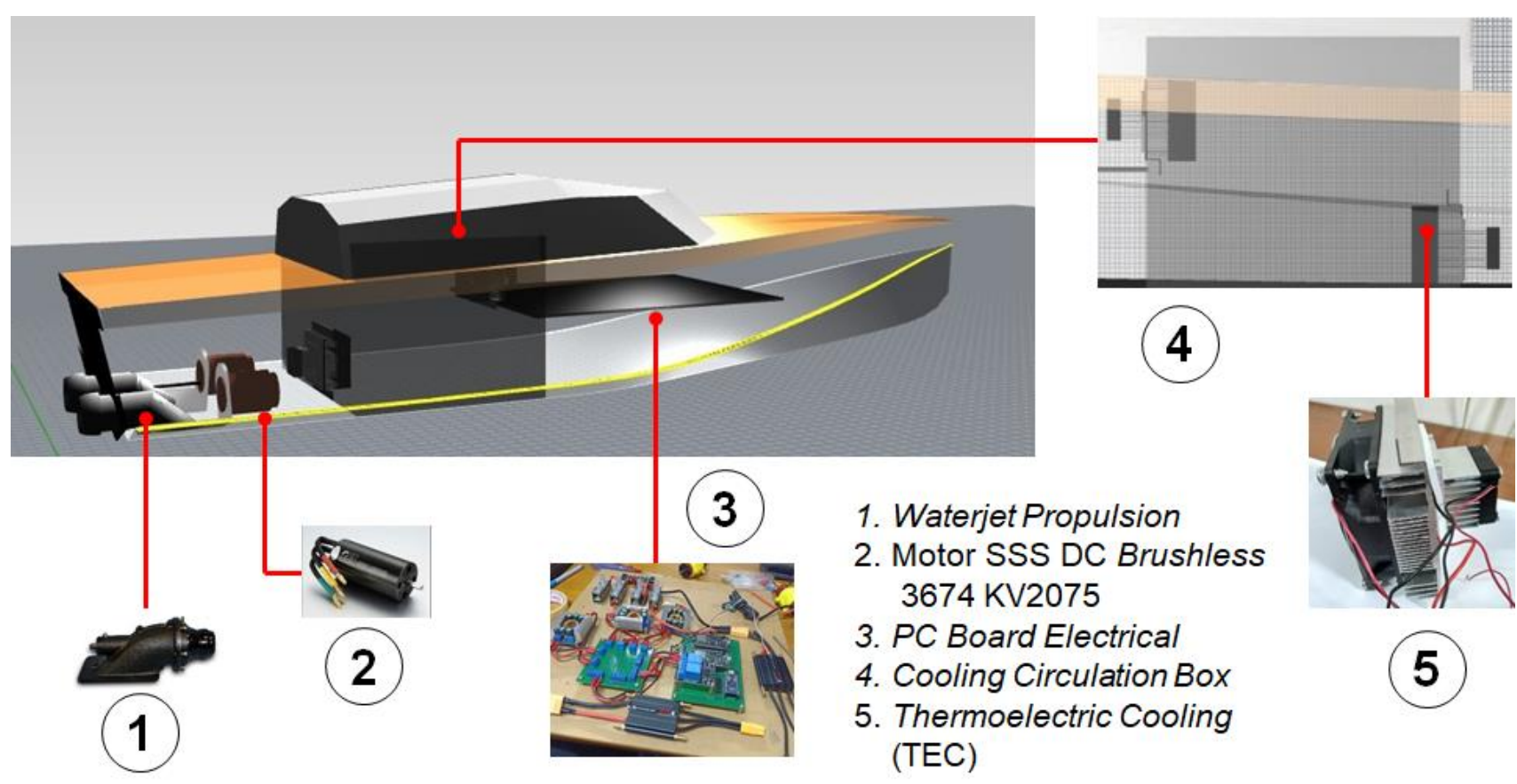

Fig. 2. The general arrangement of an electronic and cooling system of the designed USV

\subsection{Design of Thermoelectric Cooler}

In this study the dimensions of the cooling circulation box installed with a thermoelectric cooler to circulate the cold air to the electric motor are 0.3 meters long, 0.2 meters wide and 0.2 meters high. The cooling circulation box has designed with the function of flowing hot air out of the room. The equipment components contained in the cooling circulation box are two heatsinks, two exhaust fans, a water-cooling hose, and two water block units. While the cold side is faced with an electric motor that is used as a water jet propulsion system, the components of the cold side are $12 \mathrm{~V} \mathrm{TEC}$ 12706 Peltier units, two heatsink units, and two exhaust fan units. In designing this thermoelectric cooling system, specification requirements must be considered to ensure the cooling system that is made will meet the cooling criteria in the ship. Based on preliminary analysis and data obtained, some of the requirements specifications that must be met are 
i. The heat inside the Cooling Circulation Box must be able to be discharged back out of the ship,

ii. Able to cool ship space especially in electrical and mechanical components in the range of 10 ${ }^{\circ} \mathrm{C}-30{ }^{\circ} \mathrm{C}$,

iii. The use of small electric power,

iv. Construction of a cooling device that is simple and easily repaired,

v. Laying the cooling device facing electrical and mechanical components so that cooling can be spread evenly,

vi. Using raw materials that are easily available on the market.

After considering the existing limitations, the thermoelectric cooler design that is used is to use a cooled-water system that is flowed to an electric motor. The designed thermoelectric cooler is shown in Figure 3. After the thermoelectric cooler design has been assembled, the experimental test was carried out with the experiment scheme shown in Figure 4. The experimental test is conducted to obtain the thermoelectric cooler device performance data to determine the cooling performance and heat dissipation effectiveness of the Cooling Circulation Box. The electric power of the thermoelectric cooler set is supplied by a DC power supply connected to the Peltier and two fans, and temperature data collection uses a thermocouple linked to a commercial data logger Mastech MS6514. Several trials were carried out with varying the power supply for Peltier and fans, but not all results are presented in this paper. Data collection includes data collection with variations in fan power and data collection with variations in use only with water cooling, only fan, and combining water cooling with fans. The greater the fan's power, the bigger the air discharge will be. On the cold side, the greater the power of the cooling air fan will be more and more at the same time.

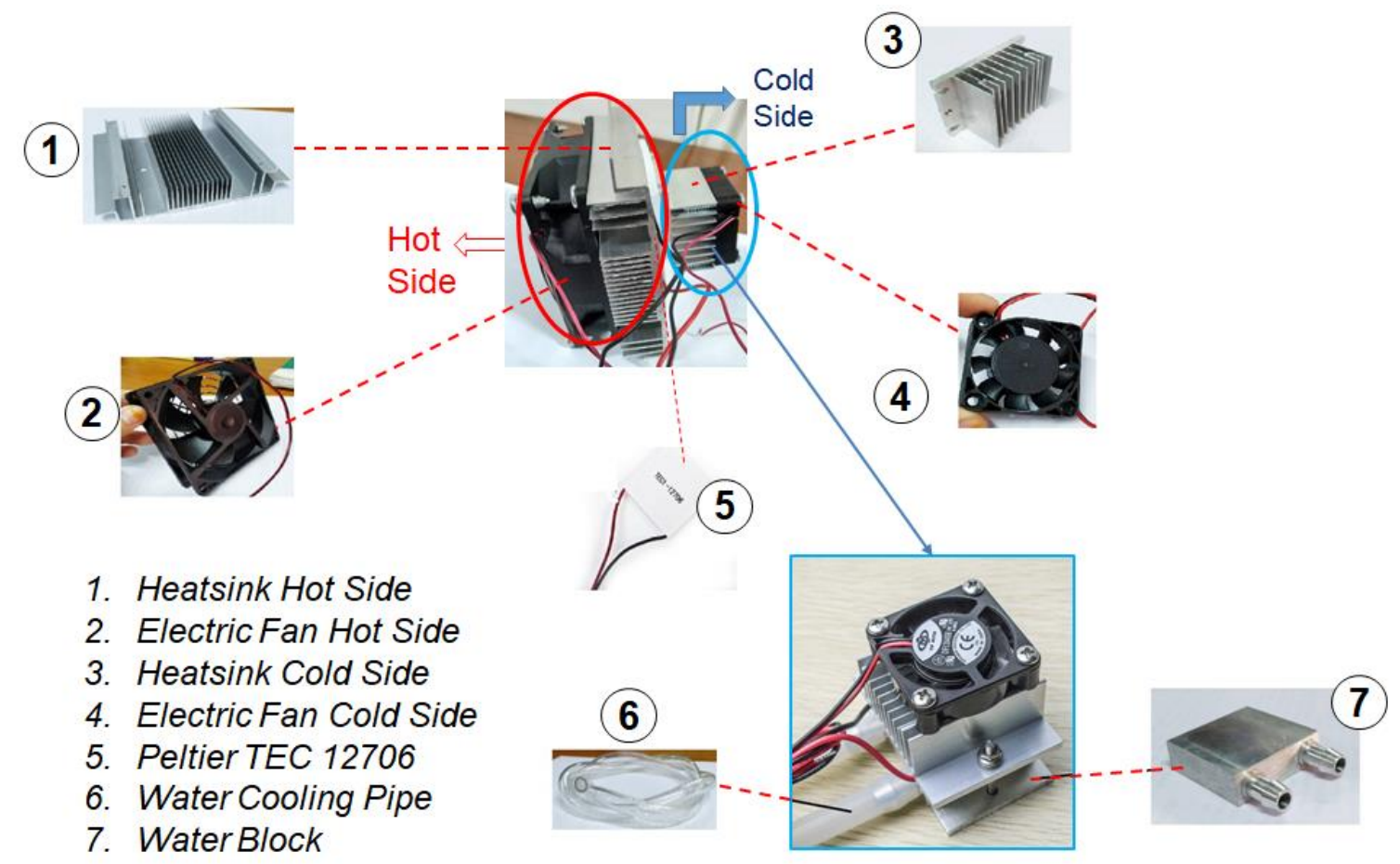

Fig. 3. Design of mini thermoelectric cooler 


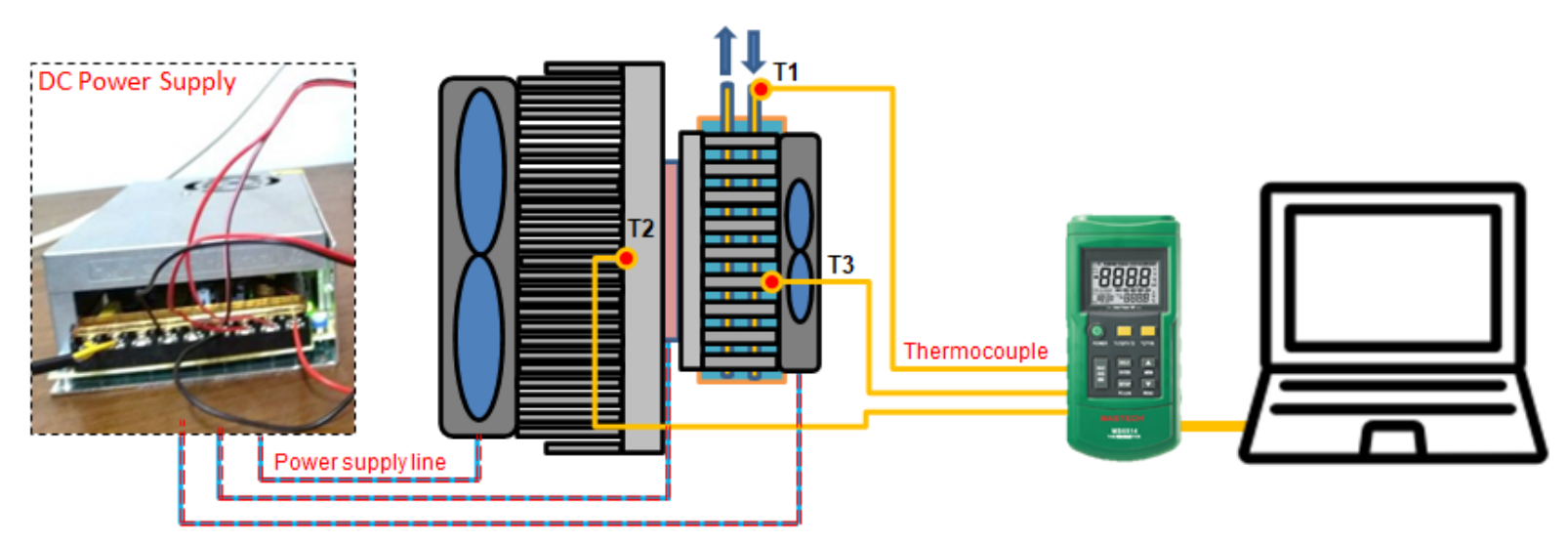

Fig. 4. Design of experimentation of thermoelectric cooler

\section{Results and Discussion}

\subsection{Initial Temperature inside USV}

The experiment was carried out in the experimental basin by placing a temperature sensor inside the USV near the electrical circuit. Experiments were carried out in calm water conditions for 30 minutes continuously. From the environmental data, it is known that the ambient temperature is 36 ${ }^{\circ} \mathrm{C}$. Temperature data is recorded continuously and shown in Figure 5 . From the results it is seen with a continuous operational pattern for 30 minutes, the room temperature in USV reaches $39{ }^{\circ} \mathrm{C}$, this indicates the influence of rotation electric motors that cause heat inside the USV. From the recorded of the room temperature inside the USV, the increased temperature used as reference data for the performance of the thermoelectric cooler, the target of room temperature decreases minimal $3{ }^{\circ} \mathrm{C}$.

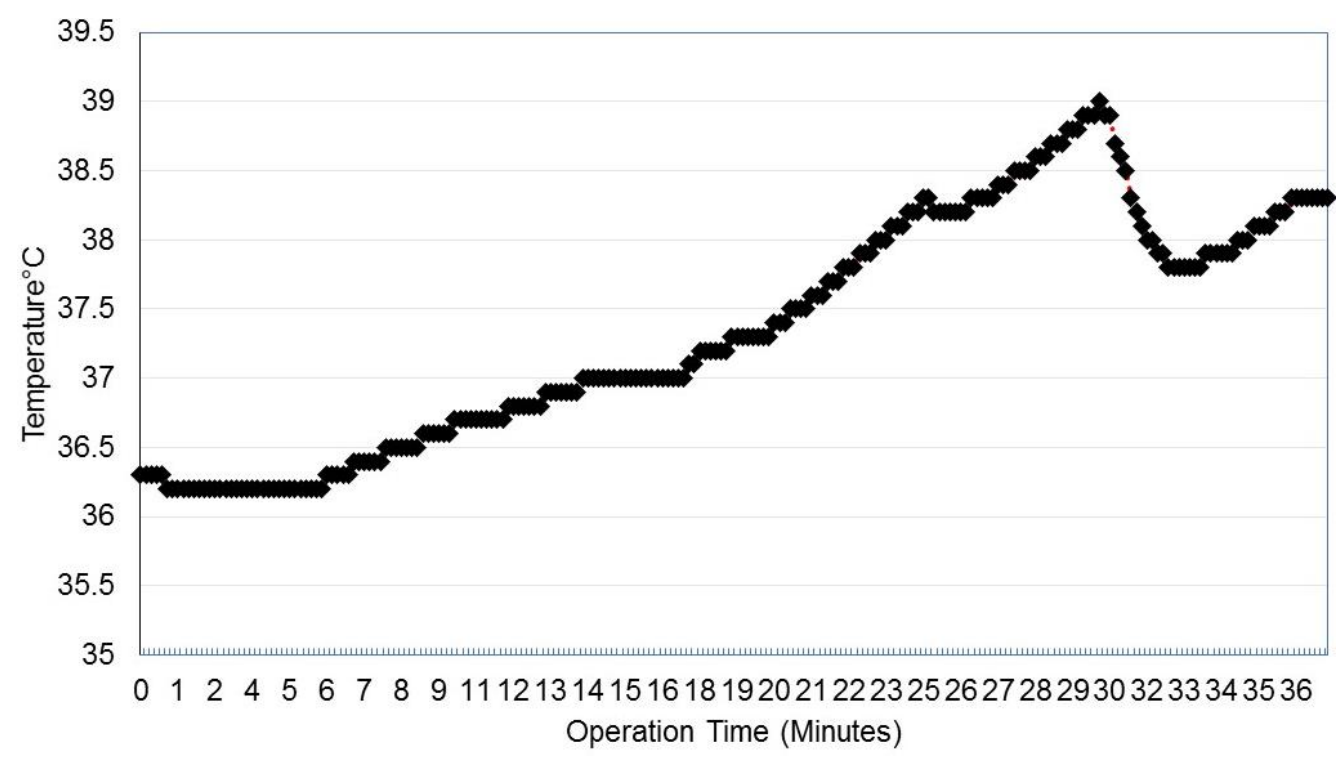

Fig. 5. The initial temperature inside USV during operation

\subsection{Performance of Thermoelectric Cooler}

After obtaining preliminary data on the temperature inside USV, this section will discuss the basic performance of thermoelectric coolers that have not been installed into USV. In this experiment it was measured only on the hot and cold sides of the thermoelectric cooler with a time of about 30 minutes, the measurement results shown in Figure 6 . The performance measurements of the 
thermoelectric cooler show that this tool is functioning properly, a significant temperature difference starts after the 5 th minute, the temperature on the cold side begins to fall from room temperature $28^{\circ} \mathrm{C}$ down to $13^{\circ} \mathrm{C}$. On the hot side temperature increases tend not significant, after 5 minutes the temperature starts to rise from $30^{\circ}{ }^{\circ} \mathrm{C}$ to $33{ }^{\circ} \mathrm{C}$, after which the temperature tends to be constant. After the 10th minute, both the hot side and cold side temperatures begin to stabilize at $31{ }^{\circ} \mathrm{C}$ and $12{ }^{\circ} \mathrm{C}$, it can be seen that the temperature difference between the cold side and hot side was reached $19{ }^{\circ} \mathrm{C}$, this certainly exceeds the target of the expected temperature reduction. After obtaining this result, the thermoelectric cooler was set into the inside of USV, this experiment was carried out to show the effectivity of the cooling performance inside the USV.

Experiments carried out are transferring heat from the electric motor to the cold side of the thermoelectric cooler. Heat transfer occurs through water media connected with the heat pipe around the electric motor, which is considered as a source of heat, then the heat pipe is connected to the cold side of the thermoelectric cooler. Measurements were made at three points: T1 is in the heat pipe of the electric motor, T2 is on the hot side of the thermoelectric cooler, and T3 is on the cold side of the thermoelectric cooler. The results of the measurements can be seen in Figure 7. From this result, it can be seen the temperature at each point starts to be constant after the 10th minute, after this time the thermoelectric cooler is stable runs. Therefore, the data used as analysis material is taken after the tenth minute, the data before that time is ignored. The average temperature at the measured point at $\mathrm{T} 1, \mathrm{~T} 2$, and $\mathrm{T} 3$ are $39.6^{\circ} \mathrm{C}, 36.6^{\circ} \mathrm{C}$, and $13.3^{\circ} \mathrm{C}$, respectively. The temperature difference on the hot side and the cold side reach $23.2^{\circ} \mathrm{C}$, thus the temperature difference between the cold side and the heat pipe from the electric motor reaches $26.3^{\circ} \mathrm{C}$. These results show that due to the heat from the electric motor, causing the temperature difference on the cold and hot sides tends to rise. From this result can be assumed that the application of a thermoelectric cooler potentially effective to decreased the electric motor temperature by as much as $26.3^{\circ} \mathrm{C}$ by neglected the heat loss due to convection. Further studies related to heat loss will greatly assist the analysis to determine the effectiveness of the value of temperature reduction due to the thermoelectric cooler.

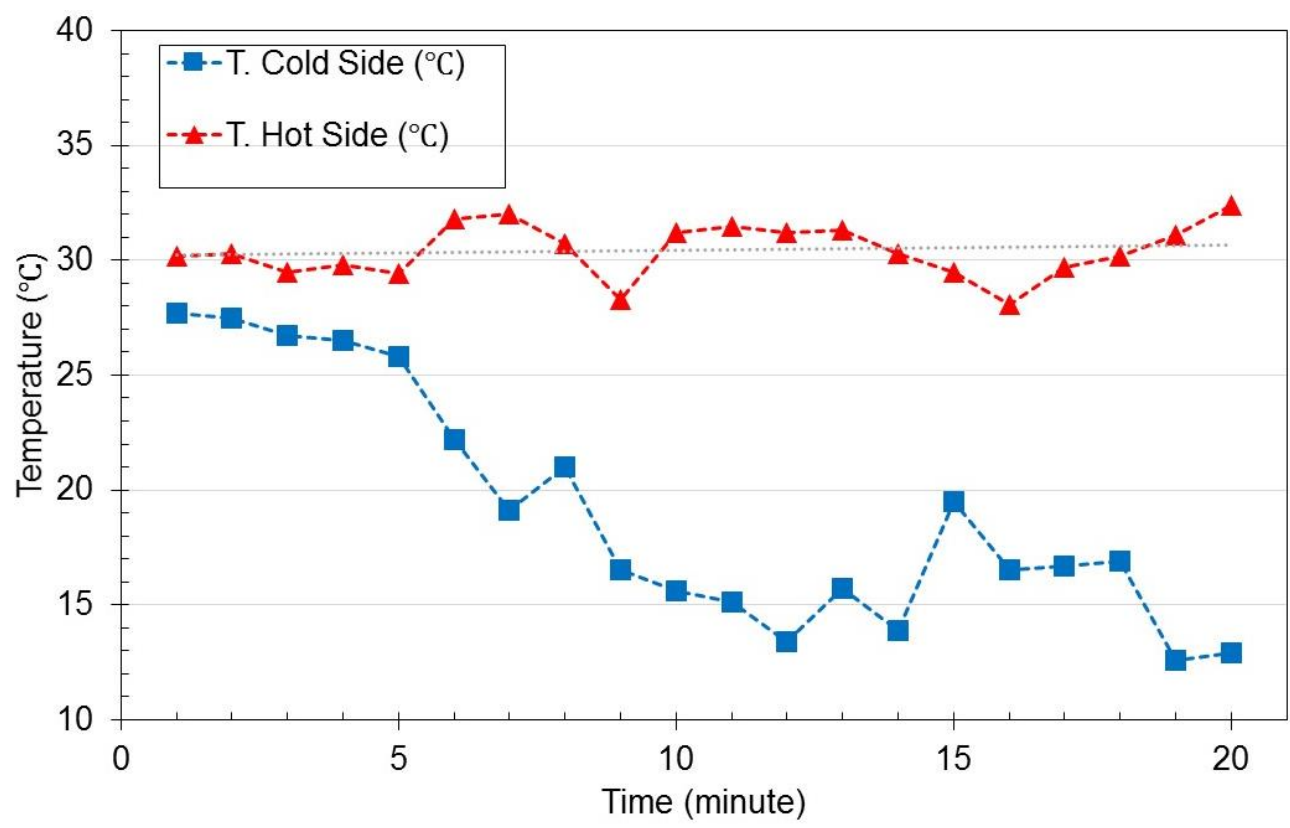

Fig. 6. The temperature on the hot side and cold side of the thermoelectric cooler 


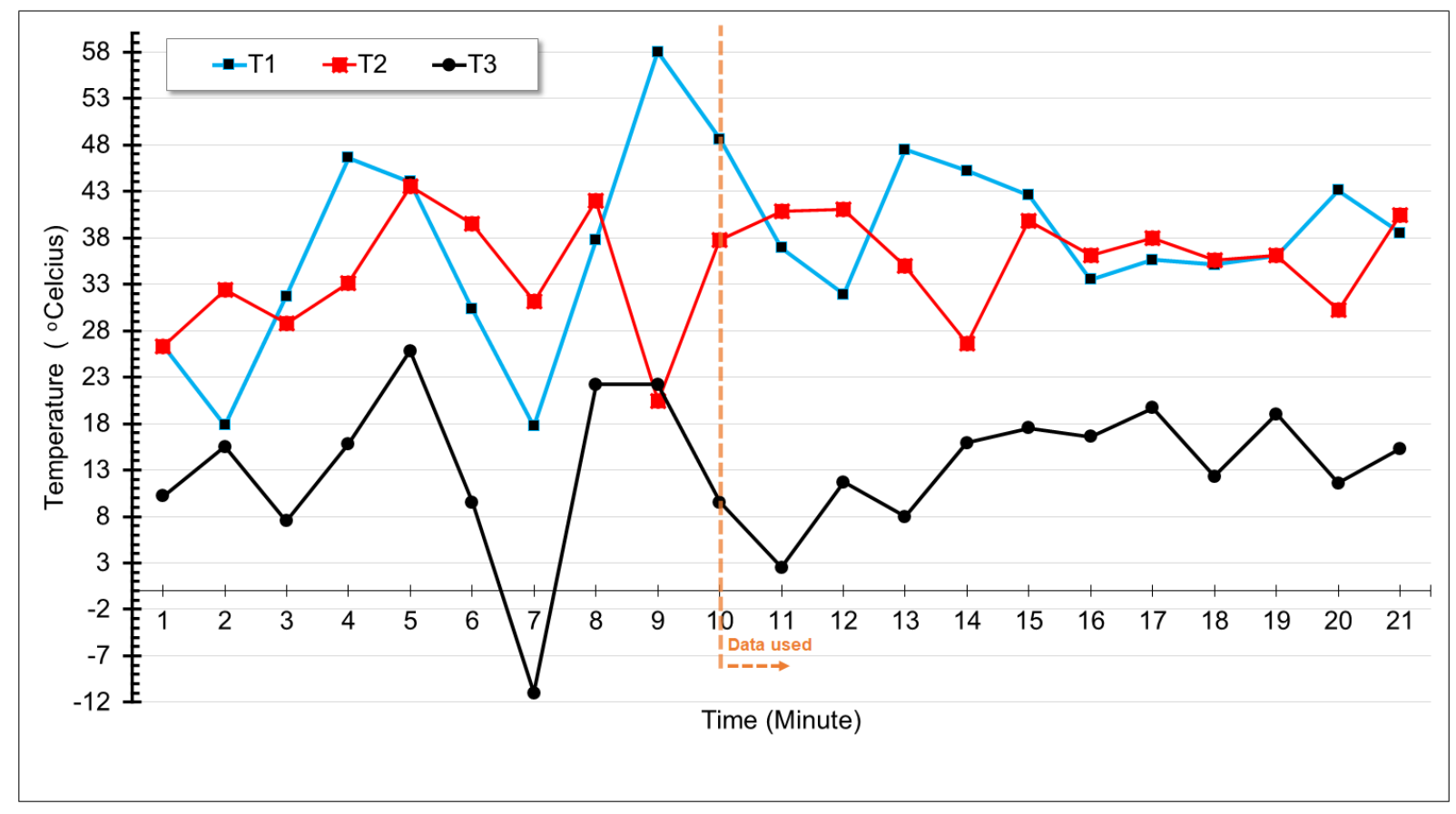

Fig. 7. The temperature on the thermoelectric cooler with a water-cooled system

\section{Conclusions}

An experimental study of the application of thermoelectric coolers in the unmanned surface vehicle (USV) has been performed to reduce the electric motor propulsion system. An assembled thermoelectric cooler using 12V TEC-12706 Peltier units was installed inside the USV. An experimental setup has been performed to obtain the effectivity of the thermoelectric cooler to reduce the temperature inside the USV prototype models due to heat from the motor propulsion system. The experiment result shows that the temperature difference between the cold and hot sides of the set of thermoelectric coolers can be reach $19{ }^{\circ} \mathrm{C}$. The set of thermoelectric coolers then was tested on the prototype USV models, the result shows the temperature of the electric motor potentially decrease as much as $26.3{ }^{\circ} \mathrm{C}$ with neglect the heat loss due to convection. This study provides research direction to investigate the effectivity of thermoelectric coolers by including heat loss and improve the design of thermoelectric coolers to obtain low energy consumption.

\section{Acknowledgment}

The authors would like to express our gratitude to Directorate Research and Development Universitas Indonesia (RISBANG-UI) for providing funding by the Universitas Indonesia by PUTI Q3 NKB-2011/UN2.RST/HKP.05.00/2020.

\section{References}

[1] Breivik, Morten, and Thor I. Fossen. "A unified concept for controlling a marine surface vessel through the entire speed envelope." In Proceedings of the 2005 IEEE International Symposium on, Mediterrean Conference on Control and Automation Intelligent Control, 2005., pp. 1518-1523. IEEE, 2005.

[2] Liu, Zhixiang, Youmin Zhang, Xiang Yu, and Chi Yuan. "Unmanned surface vehicles: An overview of developments and challenges." Annual Reviews in Control 41 (2016): 71-93. https://doi.org/10.1016/j.arcontrol.2016.04.018

[3] Yang, T. H., S. H. Hsiung, C. H. Kuo, Y. D. Tsai, K. C. Peng, Y. C. Hsieh, Z. J. Shen, J. Feng, and C. Kuo. "Development of unmanned surface vehicle for water quality monitoring and measurement." In 2018 IEEE International Conference on Applied System Invention (ICASI), pp. 566-569. IEEE, 2018. https://doi.org/10.1109/ICASI.2018.8394316 
[4] Yan, Ru-jian, Shuo Pang, Han-bing Sun, and Yong-jie Pang. "Development and missions of unmanned surface vehicle." Journal of Marine Science and Application 9, no. 4 (2010): 451-457. https://doi.org/10.1007/s11804-0101033-2

[5] Švec, Petr, Atul Thakur, Eric Raboin, Brual C. Shah, and Satyandra K. Gupta. "Target following with motion prediction for unmanned surface vehicle operating in cluttered environments." Autonomous Robots 36, no. 4 (2014): $383-405$. https://doi.org/10.1007/s10514-013-9370-z

[6] Campbell, Sable, Wasif Naeem, and George W. Irwin. "A review on improving the autonomy of unmanned surface vehicles through intelligent collision avoidance manoeuvres." Annual Reviews in Control 36, no. 2 (2012): $267-283$. https://doi.org/10.1016/i.arcontrol.2012.09.008

[7] Kiencke, Uwe, Lars Nielsen, Robert Sutton, Klaus Schilling, Markos Papageorgiou, and Hajime Asama. "The impact of automatic control on recent developments in transportation and vehicle systems." Annual Reviews in Control 30, no. 1 (2006): 81-89. https://doi.org/10.1016/j.arcontrol.2006.02.001

[8] Manley, Justin E. "Unmanned surface vehicles, 15 years of development." In OCEANS 2008, pp. 1-4. IEEE, 2008. https://doi.org/10.1109/OCEANS.2008.5289429

[9] Maisonneuve, J. J., S. Harries, J. Marzi, H. C. Raven, U. Viviani, and H. Piippo. "Towards optimal design of ship hull shapes." In Proceedings of the 8th International Marine Design Conference, pp. 31-42. 2003.

[10] Schneekluth, Herbert, and Volker Bertram. Ship design for efficiency and economy. Vol. 218. Oxford: ButterworthHeinemann, 1998.

[11] Budiyanto, Muhammad Arif, Muhamad Fuad Syahrudin, and Muhammad Aziz Murdianto. "Investigation of the effectiveness of a stern foil on a patrol boat by experiment and simulation." Cogent Engineering 7, no. 1 (2020): 1716925. https://doi.org/10.1080/23311916.2020.1716925

[12] Murdianto, Muhammad Aziz, Muhammad Arif Budiyanto, and Muhamad Fuad Syahrudin. "Study on the Resistance Reduction on High-Speed Vessel by Application of Stern Foil Using CFD Simulation." CFD Letters 12, no. 4 (2020): 35-42. https://doi.org/10.37934/cfdl.12.4.3542

[13] Latorre, Robert. "Ship hull drag reduction using bottom air injection." Ocean Engineering 24, no. 2 (1997): $161-175$. https://doi.org/10.1016/0029-8018(96)00005-4

[14] Kilgore, Lee A. "Marine propulsion system." U.S. Patent 4,338,525, issued July 6, 1982.

[15] Veneri, O., F. Migliardini, C. Capasso, and P. Corbo. "Overview of electric propulsion and generation architectures for naval applications." In 2012 Electrical Systems for Aircraft, Railway and Ship Propulsion, pp. 1-6. IEEE, 2012. https://doi.org/10.1109/ESARS.2012.6387448

[16] Snitchler, Greg, Bruce Gamble, and Swarn S. Kalsi. "The performance of a $5 \mathrm{MW}$ high temperature superconductor ship propulsion motor." IEEE Transactions on Applied Superconductivity 15, no. 2 (2005): 2206-2209. https://doi.org/10.1109/TASC.2005.849613

[17] Garniwa, I., B. Dipantara, M. V. Nugroho, B. Sudiarto, and N. Noorfatima. "Analysis of the effect of the motor temperature to brushless direct current motor performance on KARLING electric vehicle." In Journal of Physics: Conference Series, vol. 1376, no. 1, p. 012024. IOP Publishing, 2019. https://doi.org/10.1088/17426596/1376/1/012024

[18] Hao, Zhu, Jin Shuanbao, Wang Dong, Wang Gongbao, and Hu Pengfei. "Design and analysis of the integrated motor cooling system for shaftless propeller." IEEE Access $7 \quad$ (2019): 174573-174582. https://doi.org/10.1109/ACCESS.2019.2957104

[19] Chang, Yu-Wei, Chih-Chung Chang, Ming-Tsun Ke, and Sih-Li Chen. "Thermoelectric air-cooling module for electronic devices." Applied Thermal Engineering 29, no. $13 \quad$ (2009): 2731-2737. https://doi.org/10.1016/i.applthermaleng.2009.01.004

[20] Martínez, A., D. Astrain, and A. Rodríguez. "Experimental and analytical study on thermoelectric self cooling of devices." Energy 36, no. 8 (2011): 5250-5260. https://doi.org/10.1016/i.energy.2011.06.029

[21] Hasan, Husam Abdulrasool, Zainab Alquziweeni, and Kamaruzzaman Sopian. "Heat transfer enhancement using nanofluids for cooling a central processing unit (CPU) system." Journal of Advanced Research in Fluid Mechanics and Thermal Sciences 51, no. 2 (2018): 145-157.

[22] Kin, Looi Kar, Aklilu Tesfamichael Baheta, and Khairul Habib. "Analytical investigation of thermoelectric performance for cooling application." Journal of Advanced Research in Fluid Mechanics and Thermal Sciences 46, no. 1 (2018): 32-40.

[23] Wiriyasart, Songkran, Chootichai Hommalee, and Paisarn Naphon. "Thermal cooling enhancement of dual processors computer with thermoelectric air cooler module." Case Studies in Thermal Engineering 14 (2019): 100445. https://doi.org/10.1016/j.csite.2019.100445

[24] Liu, Di, Fu-Yun Zhao, Hong-Xing Yang, and Guang-Fa Tang. "Thermoelectric mini cooler coupled with micro thermosiphon for CPU cooling system." Energy 83 (2015): 29-36. https://doi.org/10.1016/j.energy.2015.01.098

[25] Kiflemariam, Robel, and Cheng-Xian Lin. "Numerical simulation of integrated liquid cooling and thermoelectric 
generation for self-cooling of electronic devices." International Journal of Thermal Sciences 94 (2015): $193-203$. https://doi.org/10.1016/i.ijthermalsci.2015.02.012

[26] Haryanti, Munnik, and Bekti Yulianti. "Cooling System Design Based on Thermoelectric Using Fan Motor on-off Control." In 2018 5th International Conference on Information Technology, Computer, and Electrical Engineering (ICITACEE), pp. 15-18. IEEE, 2018. https://doi.org/10.1109/ICITACEE.2018.8576958

[27] Zoui, Mohamed Amine, Saïd Bentouba, John G. Stocholm, and Mahmoud Bourouis. "A review on Thermoelectric Generators: progress and applications." Energies 13, no. 14 (2020): 3606. https://doi.org/10.3390/en13143606

[28] Fikri, Alif Hikmah, Ahmad Mufin Rosyadi, Ardanto Finkan Septa, Atikah Syahidah, Auli Rahman, Bagus Arya, Fadhil Tjitrosoemarto et al. "Makara 09 Mark II-Autonomous Surface Vehicle." Autonomous Marine Vehicle University of Indonesia, 2019. 